\title{
Diel cycle of the tropical air microbiome
}

E.S. Gusareva*, E. Acerbi, K.J.X. Lau, A. Wong, S. Kolundžija, P.B.N. Vasantha, R. Purbojati, I. Luhung, J.N. Houghton, D. Miller, N.P.E. Gaultier, C.E. Heinle, M. Clare, V.K. Vettath, C. Kee, S.B.Y. Lim, C. Chenard, W.J. Phung, K.K. Kushwaha, A.P. Nee, A. Putra, D. Panicker, M. Koh, Y.Z. Hwee, S.R. Lohar, H.L. Kim, L. Yang, A. Uchida, D. Moses, A.C. Junqueira, S.C. Schuster Singapore Centre for Environmental Life Sciences Engineering, Nanyang Technological University, 60 Nanyang Drive, Singapore

*e-mail:egusareva@ntu.sdu.sg

Key words: air microbiome, airborne microbial communities, air microbial ecosystem

Motivation and Aim: Air as an ecosystem for microbial organisms is vastly underexplored. Estimates of microbial diversity and abundance historically have relied on cultivation or amplification of gene markers. We here show that airborne microbial biomass from the Tropics can be explored by metagenomic sequencing, even when sampling short time intervals.

Results: In our five time series experiments covering 13 months period, we collected and sequencing 795 air samples that implies analyzing 1.89 billion reads of $250 \mathrm{bp}$ length. Although in our analysis we could identify less than $20 \%$ of the airborne microbial taxa, the diversity of the yet identified microbes were comparable to the human gut microbiome where about $60 \%$ of the microbial community is identified. Thus the taxonomic diversity of the air ecosystem is potentially large. Unlike terrestrial or aquatic environments, air is dominated by DNA of eukaryotes, particularly fungi of the order Asco- and Basidiomycota. Moreover, air communities remain remarkably stable over periods of time of up to 13 months, but show significant taxonomic variation within a 24 hours time scale. The observed recurrent diel fluctuations of species diversity and total biomass were shown to be driven by temperature/relative humidity changes, air $\mathrm{CO}_{2}$ concentration and rain events/lightning. The discovered dial cycle of the air microbial community was in fact so reproducible over the investigated 13-month period that a single air sample can be assigned to the actual time slot of the day it was collected, when using our data as a reference.

Conclusion: In the atmosphere microbial life is most abundantly near the planet's surface where light, temperature, $\mathrm{CO}_{2}$ and humidity are optimal. A gaseous ocean that supports life not in liquid water, but nevertheless allows for the formation of a complex ecosystem that follows the same diel patterns, as those described for the microbial communities of the world's marine systems.

Acknowledgements: This study was supported by Academic Research Fund (AcRF) Tier 3, Singapore Ministry of Education (grant number: MOE2013-T3-1-013). 